\title{
TEMPORARY HOUSING AFTER DISASTERS \\ A state of the art survey
}

\begin{abstract}
The number of natural disasters has drastically increased, causing great damages on buildings. A large number of houses have suffered damage and become unusable, causing a high number of homeless people. Housing reconstruction programmes play a decisive role on the disaster recovery and providing temporary housing is a crucial step of these programmes. During the reconstruction of permanent housing, it allows victims to have a private and secure place to return to their normal lives. This has been widely used after the largest scale disasters but it has also been greatly criticised, mainly for being unsustainable and culturally inadequate. The study aims to present a state-of-the-art survey on the topic, as well as to identify the main problems, their origin and the existing proposals to avoid them. The research also proposes some guidelines that can reduce the effects of those problems.
\end{abstract}

KEY-WORDS: post-disaster housing; temporary housing; sustainability; cultural inadequacy

\section{INTRODUCTION}

The questions about temporary housing after disasters still have not been subject to an ample discussion in the scientific literature.

The number of natural disasters has drastically increased in recent decades, having a considerable impact on the built environment. Most of the buildings affected suffer extensive damage, many of them collapse entirely, and the destruction of houses is one of the most visible effects of a disaster, causing high numbers of homeless people.

It is widely accepted that in order to bring back the livelihoods of the affected communities, the reconstruction programme should start as soon as possible (United Nations Disaster Relief CoOrdinator - UNDRO, 1982). Housing provision plays a crucial role on those programs since it is one of the most important needs for people and essential for their well-being (Barakat, 2003). A house is a space for people to live in, providing conditions for family life, comfort, protection and privacy. After a disaster the needs for housing should have a quick response because losing a house is more than a physical deprivation, it is losing dignity, identity and privacy (ibid). Providing a house is a fundamental step to establish some sense of normalcy in the life of the affected community, as well as to prevent the rising of deaths and the spread of diseases, increasing conditions to personal hygiene and giving protection against external factors like weather. Post-disaster housing provides privacy, protection and better health conditions for victims, which are decisive requirements to start a recovery and reconstruction programme after a disaster.

However, post-disaster scenarios have all the factors to produce inadequate solutions, mainly due to the need for a rapid and large-scale action under chaotic conditions (Davidson, et al., 2008), and previous studies have presented many problems related to post-disaster housing (Hidayat \& Egbu, 2010). As a consequence, very often post-disaster housing solutions fail their objectives (Kronenburg, 2009; Barakat, 2003; Lizarralde \& Davidson, 2006; Twigg, 2006). Post-disaster reconstruction is a complex process and providing temporary housing seems to be one of the most decisive tasks since it allows conditions for people to progressively return to normal life. It has been used after the most large-scale disasters, but in the same way it has been criticized for being unsustainable and culturally inadequate.

This study aims to present a state-of-the-art survey on the topic of temporary housing after disasters, identifying the main problems and the possible solutions that have been proposed. It 
also intends to propose some guidelines that can contribute for the improvement of future postdisaster temporary housing solutions.

\section{WHAT IS TEMPORARY HOUSING AFTER DISASTERS}

The definition of temporary housing is not a simple issue. According to UNDRO (1982), temporary housing is one of the eight basic types of post-disaster shelter provision. Considering temporary housing a shelter type, the classification proposed by UNDRO seems to reflect what Quarantelli (1995) considers the variety of unclear and inconsistent ways the terms shelter and housing are used in disaster literature. Proposing a definition of four distinct stages of housing that may be employed in post-disaster situations, Quarantelli (ibid) makes a distinction between sheltering and housing. While sheltering refers to a place to stay during the immediate aftermath of the disaster suspending daily activities, housing denotes the return to household responsibilities and daily routine. Based on this distinction, the four stages are: (1) emergency shelter - a place where survivors stay for a short period of time during the height of the emergency, which can be in the house of a friend or in a public shelter; (2) temporary shelterused for an expected short stay, ideally no more than a few weeks after the disaster, this may be a tent, a public mass shelter, etc.; (3) temporary housing - the place where the survivors can reside temporarily, usually planned for six months to three years, returning to their normal daily activities, and can take the form of a prefabricated house, a rented house, etc.; (4) permanent housing - return to the rebuilt house or resettle in a new one to live permanently.

This way, temporary housing can be defined as (1) an object, which means the physical structure people reside in after a disaster; (2) a part of the post-disaster re-housing programme; (3) a place that serves the function to shelter people during the period since the disaster occurs until they are resettled in a permanent place to live (Johnson, 2007a).

\section{Importance of Temporary Housing}

Following the concept of Quarantelli (1995), temporary housing is extremely important to recover after disasters, allowing people to return to their normal activities such as work, cooking, housekeeping, school, socialising, etc. (Johnson, 2007a; Arslan \& Cosgun, 2008). People are protected in shelters but cannot resume daily life, and so it is impracticable to stay longer in them. Likewise, temporary shelters may rapidly decay due to the external factors, and the need to get people out of them in order to be replaced in more durable and resistant solutions also emphasizes the importance to provide temporary housing (Steinberg, 2007). Since reconstruction can last a considerable time, there is a time gap that needs to be bridged over, and temporary housing seems to be the evident option (Johnson et al., 2010). It is the moment when uncertainty is replaced by security, allowing families to regain the necessary tranquillity to reorganise their future. This way, temporary housing helps people to feel safe and to have a social recognition (Bedoya, 2004). Temporary housing is also crucial to promote the success of the overall reconstruction, since it allows adequate time for proper community planning to reduce risk and increase sustainability for future construction (Johnson, 2008). Moreover, after a disaster it is crucial to provide temporary housing as soon as possible to offer a comfort level consistent with the common standard of living (Johnson, 2007a). This way, even in a temporary location, temporary housing is extremely important to promote the return to normalcy in a chaotic and uncertain situation after a disaster, being a necessary step in reconstruction programmes (Johnson, 2007b). 


\section{Different types of Temporary Housing solutions}

Due to its importance, it has often been used after large-scale disasters by the formal temporary housing projects or top-down approaches, which means that units are provided by governments and non-governmental organisations (NGOs). Most of these solutions are prefabricated, massproduced and standardized, and two main groups can be identified: ready-made units and kit supplies.

The ready-made units are housing solutions totally constructed in factory that just need to be transported to the site where they will be placed, see Figure 1(a). Since these solutions usually involve complex transport systems, some projects try to simplify their transportation dividing the unit in a few parts to be quickly assembled on site, see Figure 1(b).

Even so, those solutions are not easy to move to areas with difficult access and also need heavy transport systems, which is why many projects are developed based on kit solutions. The kit concept also tries to benefit from the advantages of prefabrication, but instead of producing finished units it produces the small elements that constitute the unit. The elements have to be assembled in place, thus sometimes the participation of local people in the construction or assembly process is possible, see Figure 2. This way, kit solutions facilitates transportation and the local assembly, since the elements are small, light and easy to handle.

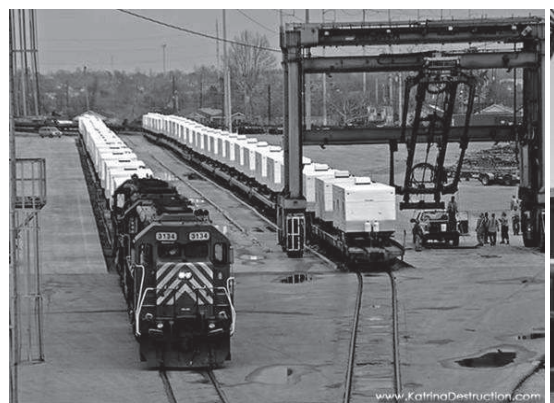

(a)

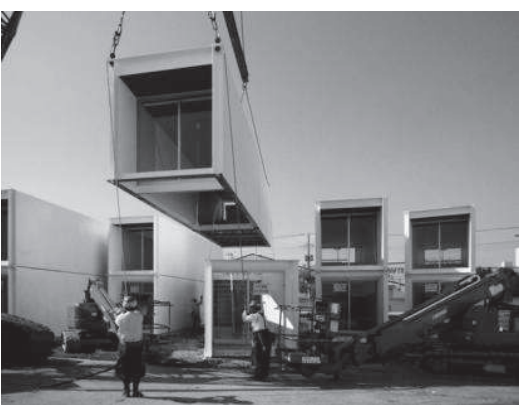

(b)

Figure. 1 - Ready-made units: (a) temporary housing units ready to be transported (source: www.katrinadestruction.com), and (b) local assembly of units (source: http://exc.ysmr.com).
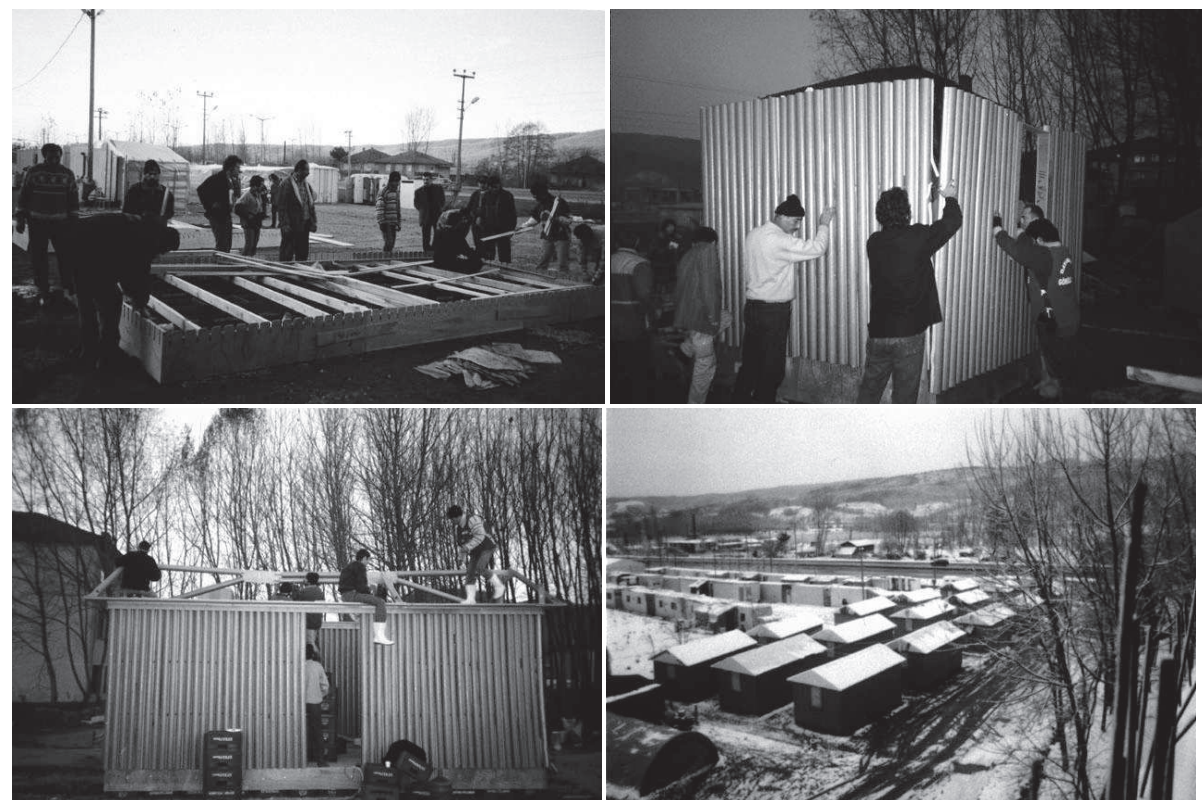

Figure 2 - Kit solutions: assembly process by local community and cluster of the Paper Log Houses designed by Shigeru Ban (source: https://archnet.org) 


\section{PROBLEMS WITH TEMPORARY HOUSING SOLUTIONS}

In spite of being a way to promote successful reconstruction programs, allowing survivors to resume their life activities, temporary housing is also a controversial issue of disasters reconstruction and has received criticism mainly due to problems of sustainability and cultural inadequacy issues (UNDRO, 1982; Barakat, 2003; Johnson, 2007a; Johnson, 2007b; Johnson, 2008; Hadafi \& Fallahi, 2010). A considerable part of post-disaster temporary housing programs have been unsustainable and culturally inadequate as a result of unsuccessful strategies, misunderstandings about users' real needs and misconceptions in dealing with local conditions and resources.

\section{Sustainability problems}

Post disaster temporary housing solutions seem to have sustainability problems in two ways: they are (1) unsustainable in terms of costs and (2) unsustainable in terms of environmental issues.

Most of the time the solutions provided are not produced in the region where the disaster occurred. Importing and transporting the units or materials required to re-house all the victims may involve extremely high costs. According to UNDRO (1982), a temporary house unit can cost more than a permanent one and some authors refer that it may be three times more expensive (Hadafi \& Fallahi, 2010). Besides the costs associated to the units, there are the expenses with the whole infrastructures needed to make temporary settlements functional (roads, water, sewerage, electricity, etc.). This way, temporary housing becomes a very expensive kind of solution in relation to its lifespan because it implies huge investments in units that will only be used during a short period of time (Johnson, 2008). As a consequence, much discussion has been centered on the question whether temporary housing is really needed, due to longer reconstruction processes, or rather an overspending that represents an important consumption of resources that are crucial for permanent reconstruction (Steinberg, 2007). As a result, the works of permanent reconstruction may be delayed and people have to stay in temporary units longer than it was planned. Since those temporary settlements are not planned for long periods, some social problems can appear (Johnson, 2007b). Beyond the questions about costs and their effects on the overall reconstruction, importing the units means long delays in the process of resettlement due to the time needed to produce, transport and place the units on the site.

Making temporary housing comfortable and resistant enough, even considering its ephemeral condition, usually means supplying structures that are more durable than the short time for which they will be required. Consequently, the units are still usable after their intended period of use and the problem is what to do with the large amount of structures. Since most of the times there is no plan for that, the units are simply dismantled or deconstructed without any concern about the future of resultant elements. That kind of procedure is a notably unproductive approach that causes great resource losses (Arslan \& Cosgun, 2007). In the same way, the site where the temporary units were placed frequently becomes greatly polluted. After the units' removal, all the infrastructure, foundations, debris, garbage, etc., should be removed in order to restore the place as it was before being occupied. Yet sometimes it is not what happens, causing great environmental consequences. The cleaning works also represents additional costs, as well as the dismantling process which is as crucial and as costly as the construction process (ibid). As a result, temporary housing becomes environmentally unsustainable due to the great amount of resources needed to build the units, the lack of solutions for them after their usage, as well as because of the site pollution. 


\section{Cultural inadequacy problems}

While trying to provide quick and economical housing, the formal sector has emphasized on standardization and technology-oriented solutions. However, those solutions are usually what a restrained group of professionals consider appropriate and not what is suitable for local inhabitants, (Lizarralde \& Davidson, 2006), neglecting cultural and local conditions as well as users needs (El-Masri \&Kellet, 2001).

Temporary housing projects continue to suffer from top-down problems of cost and cultural suitability (Johnson, 2007a). The units are usually produced in another country and sometimes intended to be used throughout the world (Barakat, 2003). This concept of a universal or standard solution is not feasible because it ignores users' real needs, climatic variations, variations in cultural values and house forms, variations in family size, etc. (UNDRO, 1982), imposing environments that may be culturally alien (Gulahane \& Gokhale, 2012). A study developed by Caia et al. (2010) shows how the shape and materials are important to match the prototype of a home. The study also states that users react according to different type of units and the relocation in temporary housing is sometimes a relevant source of psychological stress. Thus, the way users become more attached to a specific type of housing unit may benefit their psychological well-being.

When solutions do not address users' needs and expectations, they often make changes and additions to cover their necessities. Since most of the times users do not have the appropriate skills and knowledge to handle with the new materials and construction techniques, they are not able to make secure modifications or ensure the maintenance, which make units more vulnerable to future disasters, see Figure 3. In some extreme cases, people abandon the housing units provided because they cannot live in them (Boen \& Jigyasu, 2005), making all the investments in vain.

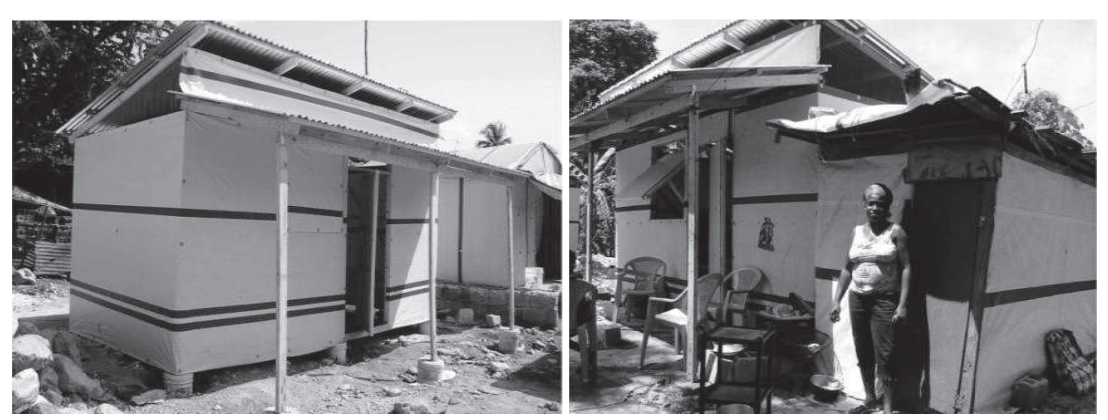

Figure 3 - Units modifications: temporary housing unit before being used and after the user modifies it (source: http://openarchitecturenetwork.org).

\section{RECOMMENDATIONS FROM EXISTING STUDIES}

Some studies have presented alternative strategies and recommendations to avoid the problems previously discussed. Most of them have insisted that principles such as community participation, usage of local resources and the development of solutions to reuse units are extremely advantageous to overcome temporary housing gaps.

Community participation and the use of local resources seem to be crucial concepts to find more sustainable and culturally adequate solutions. On one hand, local community is most of the times able to participate in reconstruction works. Indeed, studies have demonstrated that the first response to shelter needs after disasters has been provided by survivors themselves and also the idea that they are passive people waiting for help is a mistaken assumption (UNDRO, 1982; Bedoya, 2004). The usage of local materials and construction techniques allows building 
housing solutions quickly and economically because there is no need to transport the materials nor to wait for specialized workforce. This way, it is possible to avoid the delays and costs of transportation as well as costs to buy foreign materials and pay external workforce. Since the local community have the knowledge to handle local materials and local construction techniques, the construction of temporary houses can start earlier, being more economic and sustainable.

On the other hand, users' satisfaction is closely related to their participation in the assessment of their own needs (Lizarralde \& Bouraoui, 2012), being an important step to guarantee that solutions fit their expectations and are adequate to their lifestyles. In this way, local materials are more likely to be culturally and socially appropriate because people are familiar with them, and also because they provide better units' integration in the local environment. In addition, the use of local materials and workforce improves local economy, and it makes easier the maintenance and modification of the units. Moreover, using the potential of the local community for housing reconstruction helps recovering a strong community spirit, sense of pride and well-being (Barakat, 2003).

\section{Temporary housing 'second life'}

The concept of temporary means that the units are expected to be used during a predicted period of time and after that there is a need to find sustainable solutions for them. According to Johnson (2007a) there are five possibilities: (1) long-term use of the units, often considered problematic due to social dysfunctions, illegal occupancy, high crime rates, etc.; (2) dismantling units and storing them to reuse in future disasters, which may cost as much as a new unit because the costs of dismantling, transporting, storing and reassembling; (3) sell the units, or parts of them, to recover some of the costs, although certainly less than a half of the initial investment; (4) demolish the units to sell or to donate its parts, but due to their final condition they often have little value; (5) reusing the units, which may involve additional costs to dismantle, transport and reassemble in the new location.

In spite of the possible additional costs, the reuse option seems to be an advantageous strategy because the units are a relevant resource for a recovering community (Johnson, 2008).

Proposing the re-design, re-use and recycle of temporary houses, Arslan (2007) states that units should be able to be re-used after the end of usage becoming permanent. The reuse and recycle may be: (a) for the same function and without additions to be used by low income families, students, etc.; (b) for the same function with additions to enlarge the house according to dweller's expectations; (c) for different functions, such as youth camps, holiday camps, etc. (Arslan \& Cosgun, 2008). In the same train of thought, Johnson (2008) postulates that rental of temporary housing to low-income residents, reuse as new community buildings, and units acting as core for permanent housing are the most economically, socially and environmentally sustainable ways of reuse.

Independently from the functions of reuse, a 'second life' is an opportunity to enrich the high investments needed to provide units and to avoid sustainability problems. However, this is a fact that has been underestimated after many disasters, where temporary housing becomes problematic $(\mathrm{ibid})$. In order to take advantage of the reuse potential it is imperative to provide the necessary conditions during the design phase (Arslan \& Cosgun, 2008; Johnson, 2008).

\section{GUIDELINES FOR TEMPORARY HOUSING SOLUTIONS}

Based on the facts that have been presented, it seems that some guidelines can be proposed to improve the outcomes of temporary housing projects. This study proposes five main principles: 
context understanding, community participation, local resources usage, planning ahead and design beyond units.

A complete context understanding of the disaster area is a key to provide adequate housing solutions. Knowing the context means knowing all their characteristics, such as culture, traditions, social organization, economic and political systems, religious beliefs, climate, etc., and all these issues should be considered to develop temporary housing solutions. Thus, exact specifications for temporary housing solutions can only be given in a precise local context in order to provide solutions that match with their future users and environment (UNDRO, 1982; Johnson, 2007a). The starting-point in designing houses should be meeting people's aspirations and incorporating local forms of housing (Barakat, 2003).

Achieving the previous goal is dependent on community participation in the process. The users' involvement on the assessment of their needs guarantees that solutions fit their needs, expectations and local living standards. Beyond their integration in the assessment of needs, as previously discussed, their involvement in the construction works may have benefits for community recovery. However, some community-based approaches have had unexpected negative outcomes (Lizarralde \& Massyn, 2008), Thus, not all kinds of participation are synonym of positive outcomes, and participation has to be locally decided according to the context (Davidson et al., 2007).

Using local resources, such as materials, construction techniques and workforce, greatly contributes to reduce costs, to improve local economy and to provide better cultural and local integration. It also makes solutions more suitable and durable against local climate, maintaining them in a good state of repair. Moreover, it provides better maintenance and makes modifications easier for users, enabling, this way, the modification of the units according to their needs and possibilities over the time. Indeed, if carefully formulated, the indigenous and local solutions will probably be more effective, faster and better suit local needs (Gulahane \& Gokhale, 2012). The use of local resources does not mean that innovation should not be used; if properly introduced and culturally integrated, some new materials and technologies may considerably contribute to improve housing solutions after disasters (Davidson et al., 2008; Shaw et al., 2008; Garofalo \& Hill, 2008).

During the development of solutions it is crucial planning ahead, trying to create useful opportunities for their future usage. This study has discussed the advantages of some ways to reuse temporary units after their intended period of use and the importance of providing conditions to facilitate that reuse. During the designing phase it is crucial to create solutions as flexible as possible in order to make easier the required adaptations to reuse. It is also essential to make users capable of customising and personalizing their units, making additions or modifications according to their needs and possibilities. In disaster scenarios housing is often a work place for families (Kellett \& Tipple, 2000; Lizarralde \& Davidson, 2006) and flexibility is crucial to allow simple and quick transformations that make the unit able to accommodate these multifunctional spaces. Thus, flexibility is a crucial characteristic for temporary housing and has been defended by many authors (UNDRO, 1982; Kellett \& Tipple, 2000; El-Masri \& Kellett, 2001; Barakat, 2003; Bedoya, 2004; Lizarralde \& Davidson, 2006; Lizarralde \& Root, 2007; Arslan \& Cosgun, 2008; Sener \& Altum, 2009). Likewise, simple construction systems that are easy to assembly and dismantle, and that use small elements, which are easier to handle, should be preferred (Arslan, 2005).

The reversibility of the construction process proposed by Bologna (2004) is also a sustainable alternative for post-disaster housing units. This strategy proposes the possibility to re-introduce materials and spatial resources into another production cycle or to reintegrate them into the 
natural environment without production of waste or resides. Just like the reuse possibilities, the reversibility concept is only possible if properly planned ahead during the design phase.

Design beyond the unit plays a crucial role during the development of temporary houses. Having a unit that is properly adequate to users' needs and cultural issues, locally integrated, sustainable and economical does not mean that it will be well succeeded. The units' design is just an important part of the question since all the space surrounding them is extremely important for the success of the plan. The units' location has to be carefully established to ensure that people do not feel displaced, and that they are closer to their work places, services and amenities. Usually temporary housing units are built in periphery areas, which can cause social isolation and the need for extra infrastructure and services such as bus transportation (Johnson, 2007b), which represents more resources consumption. Besides the location, designing public spaces as squares, parks, gardens, etc., is decisive to provide opportunities for socializing, and that is essential to create community spirit, maintain social ties and it can be an opportunity to develop new ones. Recovering the sense of community is very important in postdisaster situations and the real meaning of the term community is in the richness of socialrelationships (Kellett and Moore, 2003). In the same way, it is important to provide services such as schools, medical assistance points, community centres, shops, coffee shops, religious buildings, etc., in order to grant all the conditions for normal life in the temporary settlement. The relation between the temporary housing units and these public spaces and buildings has to be carefully designed too. It is important to yield buffer zones from public domain to the units' private area in order to exist privacy among neighbours, as well as to facilitate social support and interaction (Caia et al., 2010). Even if these areas are not designed, free spaces should be considered so the users can create transitional areas like gardens. These spaces surrounding the units can also be used for cultivating zones or work spaces, which may be profitable for the families' economy. Since a settlement is not just a collection of individual households (Kellett and Moore, 2003), design beyond the units is a key to create greater living environments for temporary settlements.

The principles proposed above intend to be important issues to consider while temporary housing solutions are being developed, mainly to help making appropriate choices and decisions. Therefore, from the standpoint of this study it is assumed that following those principles implies to consider crucial aspects for the quality of temporary housing units, such as protection, safety, privacy, comfort, standard of living, adequate dimensions, location, thermal and sound performance, lightning, ventilation, construction quality, durability, and many others.

\section{DISCUSSION}

This study shows the unquestionable importance of temporary housing in helping affected communities to re-establish their normal life activities in a post-disaster situation. This way, it can be stated that whatever the type, after a disaster, temporary housing should be provided as soon as possible.

In spite of its importance, the solutions and strategies that have been implemented mainly by the formal sector have led to unsuccessful results with severe consequences for people and environment. The research demonstrates that those failures are mainly due to misunderstandings and misconceptions, which have resulted in the same problems of sustainability and cultural inadequacy. The study also proposes that finding solutions capable of overcoming those problems is more a question of changing the way of looking at the problem than a question of developing new technological solutions. 
It is necessary to look at temporary housing from the standpoint of the users, focusing more on people than on the units because more than a physical structure, a house is the space people inhabit. To reach that, it becomes imperative to adopt a systemic approach that considers and analyzes all the aspects related to the housing topic. That systemic approach has to be carried out in the disaster area, since precise specifications should be given in a precise local context. Besides that, the development of temporary solutions also requires a great understanding of the question at two scales: the unit scale and the settlement scale.

In spite of the fact that each situation is different and should be locally studied, this study proposes five principles that are crucial to avoid the common problems and that simultaneously can be useful considerations to look for temporary housing from a systemic approach. In order to reach the maximum benefit from those principles, they should be considered during the design phase, the crucial moment to apply concepts capable of producing successful temporary housing solutions.

Despite this research insists on the undesirable consequences of using modern production ways, such as prefabrication, mass production and standardization, as well as on the use of local and traditional techniques and materials, it also demonstrates that the development of temporary housing solutions can be an opportunity for innovation. There is space for a balance between the traditional knowledge and the introduction of new technologies.

\section{CONCLUSIONS}

The provision of temporary housing has a vital role in disaster situations but it is just a step in the reconstruction works, so it should contribute for the whole process. That contribution will only succeed if the strategies followed were capable of finding solutions for the problems that have characterized temporary housing solutions during the last decades. That is possible with the adoption of a new position, looking at temporary housing as a question that goes far beyond the providence of units. This study shows that most of the problems that have prevented temporary housing solutions to reach effective results are a consequence of solutions developed almost exclusively focused on units. Developing successful solutions of temporary units is only possible considering the large amount of issues related to the housing concept, and in turn, the temporary housing programmes only succeed if the relationships at the urban scale, that is between the units and their settlements, are carefully and effectively planned.

Due to the climate changing, it is predicted that disasters will continue to happen and as a consequence the demand for temporary housing will continue to exist too. Therefore, it is crucial to develop further research on the topic in order to develop effective and successful solutions, and the questions discussed on this study may be helpful. Moreover, within this research it becomes notable the complexity of the topic and in order to reach the desirable effective solutions, it is suggested to begin some planning actions before a disaster occurs. Having a pre-planned strategy allows managing that complexity and making some decisions without the pressure of a post-disaster scenario.

\section{ACKNOWLEDGEMENT}

The first author gratefully acknowledges the financial support of Fundação para a Ciência e a Tecnologia, FCT, through grant SFRH / BD / 73853 / 2010. 


\section{CITED WORKS}

Arslan, H. (2007). Re-design, re-use and recycle of temporary houses. Building and Environment , 42, 400-406.

Arslan, H., \& Cosgun, N. (2007). The evaluation of temporary earthquake houses dismantling process in the context of building waste management. International earthquake symposium. Kocaeli, Turkey.

Arslan, H., \& Cosgun, N. (2008). Reuse and recycle potentials of the temporary houses after occupancy: example of Duzce, Turkey. Building and Environment 43, 702-709.

Barakat, S. (2003). Housing Reconstruction after conflict and disaster. London: Overseas Development Institute.

Bedoya, F. G. (2004). Hábitat transitorio y vivienda para emergencias. Tabula Rasa., 145-166.

Boen, T. \& Jigyasu, R. (2005). Cultural Considerations for Post Disaster Reconstruction Post-Tsunami Challenges. Asian Disaster Management News, Vol. 11, No 2.

Bologna, R. (2004). Transitional housing for emergencies: temporariness and reversibility of the building process. In Proceedings of the 2004 International Conference "Improving post-disaster reconstruction in developing countries".

Caia, G., Ventimiglia, F., Maass, A. (2010). Container vs. dacha: The psychological effects of temporary housing characteristics on earthquake survivors. Journal of Environmental Psychology 30, 60-66.

Davidson, C. H., Johnson, C., Lizarralde, G., Dikmena, N., \& Sliwinskia, A. (2007). Truths and myths about community participation in post-disaster housing projects. Habitat International 31, 100-115.

Davidson, C., Lizarralde, G., \& Johnson, C. (2008). Myths and Realities of Prefabrication for Post-Disaster Reconstruction. 4th International i-Rec Conference 2008 - Building resilience: achieving effective post-disaster reconstruction. Christchurch, New Zealand.

El-Masri, S., \& Kellett, P. (2001). Post-war reconstruction. Participatory approaches to rebuilding the damaged villages of Leabanon: a case study of al-Burjain. Habitat International 25, 535-557.

Garofalo, L., \& Hill, D. (2008). Prefabricated Recovery: Post-Disaster Housing Component Production and Delivery. Without a Hitch - New Directions in Prefabricated Architecture, (pp. 64 - 71). Massachusetts.

Gulahane, K. \& Gokhale, V.A. (2012). Design criteria for temporary shelters for disaster mitigation in India. In Lizarralde, G., Jigyasu, R., Vasavada, R., Havelka, S., Duyne Barenstein, J. (eds.). Participatory design and appropriate technology for disaster reconstruction. Conference proceedings. 2010 international i-Rec conference.

Hadafi, F., \& Fallahi, A. (2010). Temporary Housing Respond to Disasters in Developing Countries- Case Study: Iran-Ardabil and Lorestan Province Earthquakes. World Academy of Science, Engineering and Technology, 66, $1536-1542$

Hidayat, B., \& Egbu, C. (2010). A literature review of the role of project management in post-disaster. Procs 26th Annual ARCOM Conference (pp. 1269-1278). Leeds, UK: Association of Researchers in Construction Management.

Johnson, C. (2002). What's the big deal about temporary housing? Planning considerations for temporary accommodation after disasters: example of the 1999 Turkish earthquakes. 2002 TIEMS Disaster Management Conference. Waterloo.

Johnson, C. (2007a). Impacts of prefabricated temporary housing after disasters: 1999 earthquakes in Turkey. Habitat International $31,36-52$.

Johnson, C. (2007b). Strategic planning for post-disaster temporary housing. Disasters 31, 435-458.

Johnson, C. (2008). Strategies for the Reuse of Temporary Housing. In I. a. Ruby, Urban Transformation (p. 323 a 331). Ruby Press: Berlin.

Johnson, C., Lizarralde, G. \& Davidson, C. (2010). A systems view of temporary housing projects in post-disaster reconstruction. Construction Management and Economics, 24:4, 367-378

Kellett, P., \& Tipple, A. G. (2000). The home as workplace: a study of income-generating activities within the domestic setting. Environment \& Urbanization , 12, 203-214

Kellet, P., and Moore, J. (2003).Routes to home: homelessness and home-making in contrasting societies. Habitat International 27, 123-141.

Kronenburg, R. H. (2009). Mobile and flexible architecture: solutions for shelter and rebuilding in post-flood disaster situations. blue in architecture 09 _ Proceedings_IUAV Digital Library.

Lizarralde, G., \& Davidson, C. (2006). "Learning from the poor”. In D. Alexander, Post-disaster reconstruction: Meeting stakeholders' interest. Florença: Università degli studdi.

Lizarralde, G., \& Root, D. (2007). Ready-made Shacks: Learning from the informal sector to meet housing needs in South Africa. CIB World Building Congress 2007, (pp. 2068-2082).

Lizarralde, G. and Massyn, M. (2008). Unexpected negative outcomes of community participation in low-cost housing projects in South Africa, Habitat International 32, 1-14.

Lizarralde, G. \& Bouraoui, D. (2012). User's participation and satisfaction in post-disaster reconstruction. In Lizarralde, G., Jigyasu, R., Vasavada, R., Havelka, S., Duyne Barenstein, J. (eds.). Participatory design and appropriate technology for disaster reconstruction. Conference proceedings. 2010 international i-Rec conference. Ahmedabad, India. Montreal: Groupe de recherche IF, GRIF, Université de Montréal. 
Quarantelli, E. L. (1995). Patterns of sheltering and housing in US disasters. Disaster Prevention and Management 4, 43-53.

Sener, S. M., \& Altum, M. C. (2009). Design of a post disaster temporary shelter unit. A|Z ITU Journal of the Faculty of Architecture 6, 58-74.

Shaw, R., Takeuchi, Y., Uy, N., \& Sharma, A. (2008). Indigenous Knowledge, Disaster Risk Reduction.

Steinberg, F. (2007). Housing reconstruction and rehabilitation in Aceh and Nias, Indonesia — Rebuilding lives.

Habitat International 31, 150-166.

Twigg, J. (2006). Technology, Post-Disaster Housing Reconstruction And Livelihood Security. (B. H. Centre, Ed.) Disaster Studies Working Paper No.15.

UNDRO, (1982). Shelter after Disaster: Guidelines for Assistance. New York: United Nations.

Vikram, B., \& Rybczynski, W. (1999). How the other half builds. In N. T. Dines, \& K. D. Brown, Timesaver standards: Site construction details manual. Montreal: McGraw-Hill. 